OP0066

RISK OF FRACTURE AND LOW MINERAL DENSITY IN ADULTS WITH INFLAMMATORY BOWEL DISEASES. A SYSTEMATIC LITERATURE REVIEW WITH METAANALYSIS

P. Szafors ${ }^{1}$, C. Lukas ${ }^{1}$, T. Barnetche ${ }^{2}$, J. Morel ${ }^{1}$, C. Gaujoux-Viala ${ }^{3}$, B. Combe ${ }^{1}$, H. Che ${ }^{1} .{ }^{1}$ Lapeyronie Hospital and University of Montpellier, Montpellier, ${ }^{2} \mathrm{FHU}$ ACRONIM, Pellegrin University Hospital, Bordeaux; ${ }^{3}$ Nimes University Hospital, Nimes, France

Background: Inflammatory bowel disease (IBD) such as Crohn's disease (CD) and ulcerative colitis (UC)) is associated with decreased mineral density caused by chronic inflammation and corticosteroid use. However, the increase of fracture risk is unknown and differs according to studies.

Objectives: The aim of our study is to assess the risk of fracture and low bone mineral density (BMD) in patients with IBD compared to the general population. Methods: A systematic search of literature up to 1 st February 2017 was conducted using databases including: MEDLINE (via PUBMED), EMBASE, the Cochrane library and abstracts from the ACR, ASBMR and EULAR congresses from 2014 to 2016. Prospective and retrospective cohort studies were included if they reported the incidence of fractures and/or the measure of BMD by dual energy X-ray absorptiometry (DEXA) (expressed in $\mathrm{g} / \mathrm{cm} 2$ ) in IBD patients in comparison with healthy controls. Meta-analysis was performed to assess odds-ratios $(\mathrm{OR})$ for each studied group using the inverse variance approach to estimate pooled OR with their $95 \%$ confidence interval. Heterogeneity was assessed according to Cochran's Q-test and I2 values. Calculations were made with the Cochrane RevMan 5.3 software. P-values less than 0.05 were considered as significant. Data was extracted by two independent investigators.

Results: The literature search identified 1165 articles and no congress abstracts; a manual search did not retrieve any articles. Finally, 25 studies met the inclusion criteria. 9 of them reported 2065 fracture events among 42,615 IBD patients and 4825 fracture events among 203240 healthy controls. Global risk of fracture was increased in IBD patients compared with controls with pooled OR at $1.50(95 \% \mathrm{Cl}$ : 1.10 to $2.05 ; p=0.01)$. The pooled OR of vertebral fracture was $2.26(95 \% \mathrm{Cl}: 1.04$ to $4.90 ; \mathrm{p}<0.001)$. Fracture risk was not significantly increased for any other site (arm, hip, wrist). The analysis of 17 studies concerning BMD showed the significant decrease of BMD and Z-score at three sites. At femoral neck, mean difference (MD) of BMD was -0.05 ( $95 \% \mathrm{Cl}$ : -0.08 to -0.02 ; $p=0.001$ ) and MD of $Z$ score $-0.48(95 \% \mathrm{Cl}:-0.64$ to $-0.33 \mathrm{P}<0.00001)$. At total femur, this values was respectively $-0.08(95 \% \mathrm{Cl}:-0.11$ to $-0.05, \mathrm{p}<0.00001)$ and $-1.01(95 \% \mathrm{Cl}$ : -1.52 to $-0.50 ; p=0.07)$, and at lumbar spine $-0.06(95 \% \mathrm{Cl}:-0.10$ to -0.03 , $\mathrm{p}=0.0003)$ and $-0.51(95 \% \mathrm{Cl}:-0.68$ to $-0.34 ; \mathrm{p}<0.0001)$.

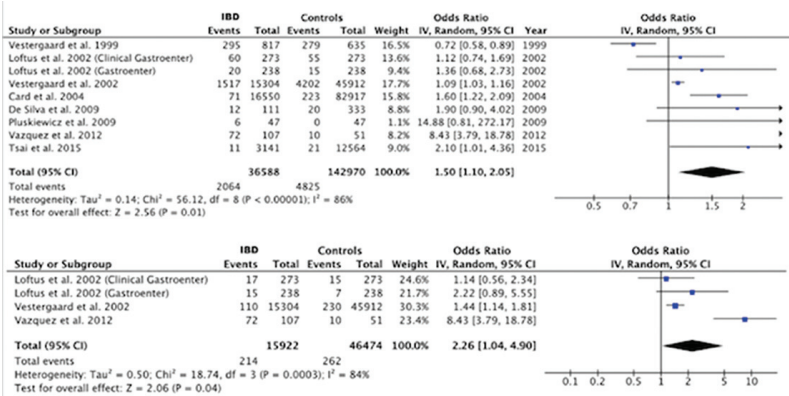

Conclusions: IBD patients have an increased risk of fractures, especially vertebral ones, suggesting the need for regular follow-up and preventing measures.

Acknowledgements: This work was initiated during sessions on performing meta-analyses organised by AbbVie. AbbVie had no role in the study design or in the collection, analysis, or interpretation of the data, the writing of the manuscript, or the decision to submit the manuscript for publication. Publication of this article was not contingent upon approval by AbbVie. This study was not financially support by AbbVie.

Disclosure of Interest: None declared

DOI: 10.1136/annrheumdis-2018-eular.2553

\section{OP0067 \\ DICKKOPF-1 (DKK1) SERUM LEVELS AND BONE QUALITY (TBS EVALUATION) IN PATIENTS WITH SYSTEMIC SCLEROSIS AND RHEUMATOID ARTHRITIS}

A. Casabella ${ }^{1}$, B. Ruaro ${ }^{1}$, S. Paolino ${ }^{1}$, C. Pizzorni ${ }^{1}$, E. Alessandri ${ }^{1}$, C. Seriolo ${ }^{2}$, D. Fasciolo ${ }^{1}$, G. Botticella ${ }^{2}$, L. Molfetta ${ }^{2}$, P. Odetti ${ }^{2}$, B. Seriolo ${ }^{2}$, M. Cutolo ${ }^{1}$. ${ }^{1}$ Department of Internal Medicine, Di.M.I. Polyclinic Hospital, San Martino, University of Genoa, Genoa Italy, Research Laboratory and Academic Division of Clinical Rheumatology, ${ }^{2}$ Department of Internal Medicine, Di.M.I. Polyclinic Hospital, San Martino, University of Genoa, Genoa Italy, Osteoporosis, Bone and Joint Disease Research Center, CROPO, Genova, Italy

Background: Systemic sclerosis (SSc) as well as rheumatoid artrhritis (RA) patients present an increased risk of osteoporosis (OP) as a result of the chronic inflammatory state, low vitamin $D$, immobilisation and other causes. The $\mathrm{Wnt} / \beta$ catenin pathway is signalling identified like a key promoters of the osteoblastogenesis hence of the new bone formation in inflammatory conditions. Dickkopf- 1 (DKK1) is a natural inhibitor of Wnt signalling pathway that could be involved in promoting osteoclastogenesis through suppression of osteoprotegerin. ${ }^{1}$ Trabecular Bone Score (TBS) is an index of bone quality extracted from dual-energy $\mathrm{X}$-ray absorptiometry (DXA) analysis. ${ }^{2}$

Objectives: In this study, bone mineral density (BMD) and Dkk-1 levels were evaluated in SSc patients, in order to investigate possible associations between systemic OP and/or osteopenia and Dkk-1 concentrations, according to their different nailfold videocapillaroscopic (NVC) patterns of microangiopathy (NVC patterns 'Early', 'Active', and 'Late') ${ }^{3}$ in SSc patients and to compare the results regarding bone quality with RA patients and healthy subjects (CNT).

Methods: Eighty-four SSc patients, 98 rheumatoid arthritis (RA) and 60 CNT were studied. Dkk-1 serum levels were measured by ELISA methods (Quantikine Human DKK-1 Immunoassay R and D System, Minneapolis, USA). Bone Mineral Density (BMD, $\mathrm{g} / \mathrm{cm}^{2}$ ) of the lumbar spine ( $\left.\mathrm{L} 1-\mathrm{L} 4\right)$ was analysed by dual-energy X-ray absorptiometry (DXA) scan. Lumbar spine bone quality was derived from each spine DXA examination using the TBS analysis. Nailfold videocapillaroscopic (NVC) patterns were analysed as previous reported. ${ }^{3} 25$ hydroxyvitamin $D$ $(25(\mathrm{OH}) \mathrm{D} \mathrm{ng} / \mathrm{ml})$ serum concentration was evaluated in all subjects.

Results: Serum DKK-1 levels were significantly higher in patients with SSc than in CNT $(2892 \pm 1121 \mathrm{pg} / \mathrm{ml}$ vs $2044 \pm 692 \mathrm{pg} / \mathrm{ml}, \mathrm{p}<0.007)$. Dkk-1 levels were statistically significantly higher in patients with 'Late' SSc pattern than in those both 'Active' and 'Early' pattern $(3467 \pm 954.1 \mathrm{pg} / \mathrm{ml}, \quad 2290 \pm 487.8 \mathrm{pg} / \mathrm{ml}, 1827$ $\pm 888.3 \mathrm{pg} / \mathrm{ml}$ respectively, $p<0.0001)$. A negative correlation between Raynaud's phenomenon duration (years expressed) $(p<0.01)$ and Dkk-1 levels $(p<0.001)$ was also observed).TBS values were found statistically higher in SSc with a 'Early' NVC pattern, compared to the 'Active' or 'Late' pattern, ( $p<0.001)$. Only in the 'Late' NVC pattern group a significant negative correlation was observed between TBS and Dkk-1 values $(p<0.001)$. No statistical significant difference was observed in the three groups about DXA values $(p=0.13$, for all areas). Serum levels of $25(\mathrm{OH}) \mathrm{D}$ were statistically significantly higher in patients with 'Early' SSc pattern than in those both 'Active' and 'Late' NVC pattern $(19.1 \pm 7.5,15.1$ $\pm 5.3,12.1 \pm 7.1$ respectively, $p=0.002$ ).

Conclusions: The data obtained showed a significantly Increased of Dkk-1 serum concentrations together and a decreased bone mass (lower TBS and BMD) in SSc patients compared to CNT. The bone quality seems lower in SSc patients with more altered microvasculature ('Late' NVC pattern).

\section{REFERENCES:}

[1] Krishnan V, et al. J Clin Invest 2006;116:1202-9.

[2] Roux JP, et al. Osteoporosis Int 2013;24:2455-60.

[3] Cutolo M, et al. J Rheumatol 2000;27:155-60.

Disclosure of Interest: None declared

DOI: 10.1136/annrheumdis-2018-eular.5555

\section{OP0068 SHORT TERM EFFECTS OF AMBIENT AIR POLLUTION ON OSTEOPOROTIC HIP FRACTURE. AN ECOLOGICAL STUDY IN A PERIOD OF 16 YEARS}

R. Mazzucchelli ${ }^{1}$, E. Pérez-Fernandez ${ }^{1}$, J. Quirós ${ }^{1}$, N. Crespí Villarías ${ }^{2}$, A. GarcíaVadillo ${ }^{3} .{ }^{1}$ Hospital U. Función Alcorcón; ${ }^{2}$ C.S La Rivota, Alcorcón; ${ }^{3}$ H. U. La Princesa, Madrid, Spain

Objectives: To examine the short-term effects of outdoor air pollution on the incidence of osteoporotic HFx in a southern European region. 